\title{
Cartografia: \\ ESTRATÉGIAS DE PRODUÇÃO DO CONHECIMENTO
}

\author{
Vitor Martins Regis $\star$ \\ Tania Mara Galli Fonseca $\star$
}

\begin{abstract}
RESUMO
Este artigo trabalha o conceito de cartografia procurando propor um estilo singular de produção do conhecimento que desenvolve a ideia de expansão da vida cunhada por Espinosa. Inicialmente, nós criticamos algumas influências filosóficas de Platão e Descartes no campo das discussões metodológicas como ainda constituintes de modos de vida que tendem à homogeneização calcados na racionalidade moderna. Depois disto, utilizamos o pensamento contemporâneo de autores como Deleuze, Einstein, Heisenberg, Gödel e Prigogine para sugerir que a produção do conhecimento deve afirmar a heterogeneidade da vida, respeitando preceitos éticos, estéticos e políticos.
\end{abstract}

Palavras-chave: cartografia; método; processos de subjetivação.

\section{Cartography: STRATEGIES OF KNOWLEDGE PRODUCTION}

\begin{abstract}
This article deals with the concept of cartography in order to propose a singular style of knowledge production which develops Spinoza's idea of life expansion. At first, we criticize some of the philosophical influences of Plato and Descartes on the field of methodological discussion as constituents of a homogeneous and moralistic way of life. These influences are characterized by the logical modern rationality. After that, we use the contemporary thoughts of authors such us Deleuze, Einstein, Heisenberg, Gödel and Prigogine to suggest that the knowledge production should state heterogeneity of life, respecting ethical, aesthetical and political parameters.
\end{abstract}

Keywords: cartography; method; processes of subjectivation.

^ Psicólogo. Mestrado em Psicologia Social e Institucional pela Universidade Federal do Rio Grande do Sul. Professor de psicologia da Faculdade Capixaba de Administração e Educação. UNICES. Avenida Vitória, 800 - Horto. Vitória - ES.

E-mail:vitorregis@hotmail.com

$\star \star$ Psicóloga. Doutorado em Educação pela Universidade Federal do Rio Grande do Sul e Pósdoutorado pela Universidade de Lisboa. Professor titular da Universidade Federal do Rio Grande do Sul. Faculdade de Educação Av. Paulo Gama, s/n. Porto Alegre, RS.

E-mail: tfonseca@via-rs.net 


\section{Cartografia: estratégias de PROduÇÃo do CONHecimento}

Com seu perdão, Seu Nando, a roupa preta não fez o senhor padre. Esse gibão de couro não vai fazer o senhor cangaceiro não.

Não se assuste, Manuel. Eu agora viro qualquer coisa (CALLADO, 1978).

Sou um técnico, mas tenho técnica só dentro da técnica. Fora disso sou doido com todo direito a sê-lo. Com todo direito a sê-lo, ouviram? (PESSOA, 1998).

Os artifícios para a construção do conhecimento, descritos neste artigo, decorrem de uma concepção principal: nosso compromisso é com a expansão da vida, ${ }^{1}$ com o aumento da sua potência de diferir. Portanto, ao primeiro sinal de que o desenvolvimento das atividades passa a não cumprir este objetivo, o pesquisador, os instrumentos e os modos de ação devem ser problematizados com mais atenção e reinventados.

É respeitando esse compromisso fundamental que optamos por, ao contrário de falar em metodologia, usar o conceito de estratégia para discorrer sobre a maneira como procederemos em relação à produção do conhecimento. Esta modificação afirma a inoperância que sentimos revestir a ciência régia frente ao desejo de viabilizar a expansão da vida.

Nosso pessimismo decorre do tratamento programático que quase sempre é utilizado para constituir os saberes, e consequentemente, calçar as intervenções realizadas no plano das ciências humanas. Consequentemente porque, para um modo de fazer ciência alimentado pela tradição de pensamento platônico-racionalista, fica demarcada uma compreensão linear - em termos de sucessividade - e, ao mesmo tempo, rachada - em termos de causa e efeito - das relações entre conhecer e fazer ciência. Quando, na realidade, é inegável uma articulação complexa, de retroalimentação inseparável, entre os dois movimentos.

Se entendemos que os movimentos da vida são muitas vezes, singulares e sempre, históricos, portanto, impassíveis de captura em leis e regras generalizadoras estabelecidas a priori, em vez de trabalharmos segundo uma programática que embute a variabilidade de acontecimentos em modelos pré-estabelecidos que negam a temporalidade, faremos uso de estrategismos de ação para pesquisarviver as incertezas imanentes à própria vida.

Edgar Morin (1996, p. 284) define a opção pelas estratégias de pensamento em detrimento dos programas de pensamento:

Um programa é uma sequência de atos decididos a priori e que devem começar e funcionar um após o outro, sem variar. Certamente, um programa funciona muito bem quando as condições circundantes não se modificam e, 
sobretudo, quando não são perturbadas. A estratégia é um cenário de ação que se pode modificar em função das informações, dos acontecimentos, dos imprevistos que sobrevenham no curso da ação. Dito de outro modo: a estratégia é a arte de trabalhar com a incerteza. A estratégia de pensamento é a arte de pensar com a incerteza. A estratégia de ação é a arte de atuar na incerteza.

Chamaremos o conjunto dessas estratégias de exercício cartográfico, já que nosso intuito é avaliar os deslocamentos, registrar os vestígios de encontros que sinalizem para as formações do desejo no plano social (ROLNIK, 1989). Neste sentido, não se trata de uma preocupação com origens ou fins, mas de dar passagem às intensidades que, por todos os lados, buscam meios de expressão e estabilização.

As cartografias são sempre resultados parciais, lances de uma viagem em terras estrangeiras. É essa a potência que o cartógrafo quer alcançar, de sentir-se estrangeiro dentro da própria morada, ele que de porto em porto se vê em um tempo outro, que empurra, traveste, ora rasga e ora costura o mesmo e o faz diferir.

A figura do cartógrafo que estamos construindo aproxima-se da metáfora do flâneur, trabalhada por Walter Benjamin (1986), no livro Parigi capitale del XIX secolo, por exemplo. O flâneur é um personagem urbano que sai de casa por sair, e assim, nesse trânsito sem destino traçado, atenta para a cidade e vê além da uniformidade aparente. Como o flâneur, o cartógrafo desenvolve uma capacidade de estranhamento que o desenraizará tanto da percepção do habitualmente reconhecível, como do utilitarismo herdado da sociedade capitalista moderna no que se refere à produção científica. Seus movimentos compreendem um misto de espontaneidade - porque sua atividade, como a do caçador, tem afinidade com o ócio - e autonomia - porque, como o artista, sua liberdade não pode estar disjunta das exigências da sua arte (ORTIZ, 2000).

$\mathrm{O}$ fazer metodológico nessa perspectiva - porque sempre partimos de uma perspectiva de intervenção - quer registrar os movimentos, encontros e desencontros e não a observação de objetos em suspensão.

Sujeito e objeto não são mais realidades previamente dadas, mas se produzem por efeitos de práticas. Romper com as dicotomias sujeito-objeto, indivíduosociedade, natureza-cultura implicaria a constituição de planos onde, ao mesmo tempo, sujeitos-objetos adviriam. Neste caso, o que vem primeiro é a relação, esta sim constituidora dos termos. (BARROS; PASSOS, 2000 p. 74)

Cartografar implica produzir uma diferença de natureza na forma como entendemos o fazer metodológico, realocando-o para uma posição de mobilização, maquinismo que lida com trajetos e devires e não mais com pessoas e objetos.

Assim cumpriremos o objetivo de produzir conhecimento, mas afastandonos de uma tendência filosófica - neste trabalho representada por certo espólio platônico-racionalista - calcado na analítica da verdade. Foucault (1994) evoca 
como analítica da verdade uma questão filosófica, presente desde o século XVIII, que reflete uma postura frente à construção do conhecimento preocupada em como criar as bases para o alcance da verdade.

Para tanto, depois de questionarmos os postulados fundadores da analítica da verdade em Platão e Descartes, assumiremos, em contrapartida, uma conduta engendrada a partir de um outro traço filosófico da complexa Modernidade. Somamonos aos que julgam preponderante não a procura pelo significado verdadeiro de um acontecimento, mas pensam a criação do conhecimento através do exercício crítico de avaliação desse acontecimento em sua atualidade. Considerar a produção de uma ontologia do presente da qual Foucault (1994) trata, passaria por levantar algumas questões como: Posto isto que acontece, qual plano de possibilidades podemos vislumbrar? Este acontecimento assinala conjunções lineares ou inaugura rupturas? Que signos e valores o acontecimento dispara agora em direção à humanidade?

Seguiremos, a partir deste momento, levantando questões relativas às motivações que subjazem ao pensamento de Platão e Descartes, autores influentes na constituição da analítica da verdade, tentando esclarecer alguns porquês dessa necessidade que encampamos, a de traçar uma derivação radical deste legado.

Platão propõe a criação de um mundo separado em dois, seccionando, através do método da divisão, as Ideias e as Cópias. O primeiro campo - das Ideias - diria respeito à localização das matrizes verdadeiras, dos fundamentos divinos que permaneceriam eternos e imutáveis, podendo somente ser acessado pelo pensamento. O outro campo - das Cópias - consistiria na região de abrigo dos corpos sensíveis, um domínio inferior, maculado pelos devires humanos inconstantes dos quais deveríamos nos afastar. Na melhor das hipóteses, as cópias se organizariam buscando similitude com o mundo superior das Ideias para tornarem-se cópias bem fundadas. Estamos, a essa altura, diante da primeira motivação do platonismo, a que cinde pensamento e corpo, ideia e imagem, essência e aparência, original e cópia, modelo e simulacro, inteligível e sensível.

Isto posto, passamos a analisar a operação do pensamento platonista que mais nos interessará, sua segunda motivação. Ela marca, já no interior do mundo das cópias, uma divergência cabal entre cópias e simulacros. Propondo esta divisão insuspeita, de um lado são valorizadas as boas imagens, isto é, as cópias alinhadas aos modelos, e de outro, as imagens anômalas, ou seja, os simulacros, os falsos pretendentes ou pretendentes sem pretensão são desqualificados.

De acordo com Maria Cristina Lavrador (1999), a dialética platonista, construída a partir do modelo da representação, não funciona por meio da colocação de contradições, mas através do estabelecimento de rivalizações. Lavrador (1999, p. 19) afirma que a opção do platonismo é a de:

assegurar o triunfo das cópias-ícones sobre os simulacrosfantasmas, impedindo-os de se insinuar por toda parte, procurando excluí-los e exorcizá-los. O platonismo funda o domínio da representação, que é constituído pelas cópiasícones e definido numa relação intrínseca ao modelo 
ou fundamento. O modelo é o Mesmo, por exemplo, 'a Justiça não é nada além de justa'. Isto é, a Justiça (o fundamento abstrato) possui a qualidade de justo (o objeto da pretensão), mas lhe dá aos justos (o bom pretendente). $\mathrm{O}$ bom pretendente tem a qualidade de justo quando se funda sobre a essência - a Justiça. A cópia é o Semelhante, é a similitude exemplar de um original idêntico.

É importante frisar que o platonismo, ao eleger as cópias com semelhança em lugar dos simulacros, processa um sistema ditador de valoração onde as primeiras são identificadas por uma positividade e os últimos selados negativamente. Esse julgamento de valor, engendrado pelo pensamento da representação, força a pressuposição das formas sensíveis a ideais pré-conceitualizados, limitando de maneira autocrática a possibilidade de viver ao acaso, de devir outro segundo as forças e os fluxos que nos atravessam. São, justamente, os simulacros que comportam a potência de diferir que alimenta a expansão da vida.

$\mathrm{Na}$ Grécia Antiga, antes da hegemonização das ideias de Platão, o que nunca significou que todos pensassem na sua esteira em qualquer tempo, a ideia de consciência de si não se configurava como algo do domínio privado, pois tal consciência implicava sempre relação com algo do domínio público. Dessa forma, não se tratava de refletir personalisticamente, uma vez que a subjetividade era forjada no encontro com o outro.

Se, por exemplo, levarmos o desejo em consideração, entre os pré-socráticos ele era pensado pelo uso que se fazia dele e dos prazeres. A conduta precisava ser dirigida pela temperança, a qualidade de governar a tensão entre as emoções e a prudência. Através da temperança, característica da conduta que não estava ligada nem ao individual nem ao social, mas ao atravessamento disso tudo, os homens chegariam à saúde e à virtude social e política. A invenção platonista subtrai a importância da conduta, retirando o exercício da liberdade do convívio coletivo e propondo a existência de uma verdade ou natureza do desejo.

Assim, se o desejo visar a outros corpos, ele passará a ser referido ao corpo caracterizado como impuro e deslocado da divindade da alma. Luiz Antonio Fuganti (1990) observa que aí está colocado um corte entre desejo e pensamento. Fuganti (1990, p. 25) escreve:

É que, para Platão, se os corpos e o desejo dos corpos pertencem ao mundo efêmero do devir, o pensamento, ao contrário, é propriedade da parte racional e permanente de nossa alma, com origem divina e portanto imortal. O desejo mundano tem por objeto os corpos corruptíveis, mas o objeto do pensamento, aquilo que o pensamento deseja, é a Idéia eterna e verdadeiramente real. É por isso que Platão buscará o ser do amor ou o verdadeiro desejo que, precisamente por ser verdadeiro, está colado à parte racional da alma, constituindo a condição para ele conhecer seu verdadeiro objeto. Estabelecerse-á assim uma ligação inédita entre desejo e pensamento pela relação que ambos devem ter com a verdade. 
Dessa forma, é interessante observar que o estatuto do pensamento em Platão é disjunto da criação da novidade, uma vez que o caminho para o alcance da verdade é permitido a conhecimentos que mimetizem a invariabilidade da Ideia. $\mathrm{O}$ pensamento fica assim restrito à contemplação e à representação de uma verdade distante que só será reconhecida mediante a purificação do corpo submetido à obediência da alma racional.

É por isso que uma das nossas atividades precisa ser a de reverter o platonismo através da exposição dos simulacros, do acolhimento da vertigem por eles insinuada, uma atividade de desobstrução que permita a efetuação da vida segundo suas próprias prerrogativas de pensamento. Uma forma de pensamento aliada e não alienada do desejo que, no que se refere mais especificamente à produção e utilização do conhecimento, queira-se problematização e não resposta, multiplicidade aberta e provisória porque é fruto de uma trajetória histórica, e não vontade de verdade finalista.

Na esteira do pensamento de Platão, Descartes, no século XVII, sem sombra de dúvida, foi um dos autores que construiu o esteio filosófico daquilo que veio a se configurar como um estilo metodológico de produção de conhecimento que aspira à verdade. Isto, apesar da matriz racional que orienta tal modo de conceber a ciência ter se organizado no século XVI, substancialmente, na esfera das ciências naturais. É somente no século XIX que este padrão de racionalidade é absorvido pelas ciências sociais nascentes.

O pensamento cartesiano reatualiza o platonismo porque continua seguindo das ideias para as coisas, mantendo a metafísica como o porto seguro da ciência. Só que, por sua conta, ele vê na matemática algo a fundamentar a metafísica. Desta observação decorrem dois requisitos principais. Um, conhecer passa a significar quantificar e, dois, o método científico é organizado para reduzir a complexidade dos fenômenos que estuda e, em seguida, determinar encadeamentos ordenados ante o que foi dividido.

O método cartesiano da dúvida metódica catapulta e localiza a razão como plano superior do pensamento, restringindo a produção de subjetividade ao plano da consciência como lugar de acesso ao conhecimento e à verdade. Descartes entende que a razão - inata, imutável e universal - estaria alocada na mente e, secundariamente, o corpo comportaria os desejos e afetos. A proposta de Descartes acaba estabelecendo a consciência como um invariante histórico emblemático, o de sujeito da verdade.

Trata-se de uma perspectiva científica que se organiza por meio de saberes produzidos através de noções causais que procuram prever as possibilidades de acontecimentos futuros se darem ou não. Isto, criando leis para mensurar e categorizar o que é regular e o que não costuma se repetir. Estamos falando de teorias que são marcadas, geralmente, pela utilização de noções de normalidade em que os fenômenos que se repetem são enumerados. As manifestações desviantes da regra, anômalas, ${ }^{2}$ por sua vez, são exorcizadas, anuladas pela teoria, justamente, porque assinalam a iminente criação de uma nova forma de existir. A negação da anomalia respeita a função imanente aos sistemas teóricos, essa de conservação, 
de modelização dos fenômenos subjetivos. Os sistemas teóricos e as anomalias são inconciliáveis, afinal os primeiros são sempre colocados em xeque pelas últimas, quando elas recusam o processo de normalização próprio das teorias.

O que depreendemos daí é que a analítica da verdade deseja um mundo perene em organização e em estabilidade. A instância temporal, motor dos processos de subjetivação, torna-se refém de uma tentativa de inviabilização.

Santos (1997, p. 17) utiliza a mecânica newtoniana como um exemplo entre outros possíveis, para esclarecer a operação do pensamento cartesiano:

Segundo a mecânica newtoniana, o mundo da matéria é uma máquina cujas operações se podem determinar exatamente por meio de leis físicas e matemáticas, um mundo estático e eterno a flutuar num espaço vazio, um mundo que o racionalismo cartesiano torna cognoscível por via de sua decomposição nos elementos que o constituem. Esta idéia do mundo-máquina é de tal modo poderosa que se vai transformar na grande hipótese universal da época moderna, o mecanicismo.

Desautorizamos a operação que propõe o cerceamento da multiplicidade através da padronização matemática do desejo. A analítica da verdade encurrala a vida quando a valora impura e imperfeita, destituindo sua capacidade de conhecer.

É improvável concordar com a ideia de que só equipado pelo método, visto como único instrumento passível de filtrar a verdade, o fator deformação humana seria neutralizado. De acordo com Angélica Giacomel et al (2003), o racionalismo considera o sujeito em uso do método sempre igual a si e a todos, pois, enquanto modo de apreensão do que é geral e estático, o método propõe-se a excluir do homem toda diferença e movimento, tudo que é imprevisto e contingente.

Já que discordamos radicalmente da racionalidade moderna como única forma ou modo propício de geração do conhecimento naquilo que já expusemos e compreendemos dever ser a sua finalidade, propiciar meios éticos, estéticos e políticos de que a vida se manifeste e se estabilize em acordo com os devires que dela brotam, quais alternativas divergentes estão em andamento e pedem passagem? De onde podemos partir, isto é, quais os aliados que podemos tomar para fazer da cartografia, efetivamente, um conjunto de estratégias que deem vazão à voluptuosidade da vida?

Gostaríamos de, a partir de agora, percorrer algumas das condições de possibilidade para o engendramento da cartografia como exercício de criação do conhecimento. Para tanto, passearemos entre possíveis influências referentes aos planos, primeiro da filosofia e, em seguida, das ciências naturais. Um movimento de produção de análises convergentes que portam, a despeito da variedade de campos em que foram e têm sido produzidas, o caráter transdisciplinar ${ }^{3}$ que reflete a necessidade de superação imposta pelo pensamento contemporâneo à ciência. 
No que se refere ao plano da filosofia, autores como Espinosa, Nietzsche, Bergson, Foucault e Deleuze, reconhecidos como pensadores que se esforçaram para romper com a tradição platonista e racionalista de constituição da ciência e, consequentemente, entusiastas da proposta pela construção de outras formas de estar no mundo além-moralismos, têm como influência marcante uma escola de pensamento da Grécia Antiga. Portanto, nesta parte do trabalho, nos ateremos às contribuições da filosofia pré-socrática.

Segundo Fuganti (1990), ${ }^{4}$ ao analisar a obra de Nietzsche, no século VI a.C. a conjunção entre o pensamento e a vida é festejada. Ele considera esta época a alvorada da filosofia grega. É inegável que ideias como a de que o corpo deve ser encarado como potência de afetar e potência de ser afetado, lançada por Espinosa no século XVII, ou a de que para que um corpo exista é fundamental uma conjugação que reúna força ativa e força reativa, criada por Nietzsche no século XIX, estão marcadas pelas concepções filosóficas dos pensadores pré-socráticos.

Compreendemos ser importante trazer à baila os sofistas, os cínicos, os megáricos, os estoicos e os epicuristas porque estas escolas formaram um grupo de pensadores que conjurou a ideia de indivisibilidade do exercício de pensar à construção de um corpo ativo e amante da natureza. De cara, esta primeira noção, mostra uma via filosófica completamente diversa da proposta platonista. Se, para eles, filosofar fora do corpo constituía-se algo impossível, ou seja, se a sua ideia é a de que nada se faz, nada pode existir em separado dos elementos naturais, a divisão platônico-racionalista entre corpo e mente não pode existir. Ao contrário, a concepção de vida dos pré-socráticos impõe justa relação entre um corpo que ativa o pensamento e o pensamento que afirma o corpo.

Os pré-socráticos consideravam uma grande doença, justamente, a separação entre o corpo e o pensamento. Enquanto nos séculos V e IV a.C. as tradições de pensamento socrático-platônica e pré-socrática concorrem paralelamente, a primeira espelhava a figura da razão sedentária e a segunda defendia o pensamento nômade. Fuganti (1990, p. 45-46) afirma que os pré-socráticos:

não se deixarão capturar pelas prescrições totalizadoras das cidades-Estado, nem tampouco pela moral individual do cidadão e pelos códigos que organizarão a família. Eles vão procurar, ao contrário, inventar novos modos de subjetivação e de domínio de si. Construirão uma ética com base nas potências singulares da vida e do pensamento. Pensarão a natureza como multiplicidade de forças liberta das leis humanas e indiferentes a elas, e o homem como uma natureza ligada à profundidade dos elementos, livre das ordens transcendentes e absolutas das alturas.

Para complexificar a dissonância em relação à herdade socrático-platônica que havia, até então, proposto esse grande não às alturas, os sofistas e os cínicos passam a considerar a multiplicidade de perspectivas. Eles destituem 
completamente a regra que impunha a existência de pontos pacíficos. Para eles, tudo surge e é atualizado segundo a variabilidade de pontos de vista e transmutação dos pré-requisitos filosóficos.

Já os estoicos, são os percursores daquilo que Deleuze conceituou posteriormente como "dobra". Com a noção de "superfície", em vez de deixar de lado a ideia de "profundidade", dobrarão uma sobre a outra. Esta inovação concede aos sujeitos duas faces liberadas, mas em relação intrínseca. A profundidade representada pela existência dos corpos, e a superfície pela realidade virtual, pela insistência dos acontecimentos incorporais através da linguagem. Este é mais um elemento a detonar o entendimento que coloca o ser submetido à redoma do "Eu" indiviso, tido como portador de uma identidade deslocada da realidade social da qual não pode se separar porque está sempre imerso nela.

Outra noção dos estoicos que explode as concepções platonistas e aristotélicas é não utilizar a matemática e a mecânica para pensar a filosofia e a vida, e sim, noções vitais. Fuganti (1990, p. 49) esclarece o pensamento estoico:

A essência de um corpo é definida como uma potência, uma tensão; ou, servindo-se do exemplo biológico da semente ou do ovo, ela é definida como um germe. Ora, todo germe quer germinar, expandir-se, efetuar-se, produzir frutos (seres) no devir. O limite do corpo é sempre exterior a ele, mas como efeito móvel ou flutuante de uma potência produtiva interna que se quer cada vez mais longe do seu começo. O que essa potência quer é sempre agir nas fronteiras, ultrapassar seus próprios limites, suas próprias formas, inventando novas multiplicidades, novas maneiras de ser numa superfície em devir, distendendo sempre mais o arco tenso do passado-futuro.

Para os estoicos, a natureza não possui fundamentos morais, isto é, não é possível governá-la por qualquer tipo de lei externa. Seu funcionamento, se o pensarmos por meio de leis, só pode ser remetido às leis da própria natureza. Os estoicos entendem que só o que subsiste na natureza são os corpos, estes em mistura contínua, produzindo encontros por afetação.

Em relação às análises produzidas no plano das ciências naturais, consoante Santos (1997), escolhemos enumerar quatro acontecimentos que combatem a racionalidade moderna e insinuam uma outra perspectiva emergente para o fazer científico.

Einstein, ao pensar a relatividade da simultaneidade, criou o primeiro buraco no modelo científico movido pela analítica da verdade. Em linhas gerais, o que Einstein demonstrou foi que a simultaneidade de acontecimentos distantes não pode ser verificada, pode apenas ser definida. Até ele, não poderia haver contradições nos resultados das medições porque a simultaneidade era introduzida por definição como variável arbitrária no próprio sistema de medição. Einstein detona essa axiomática, e junto dela, os ideais de espaço e tempo universais newtonianos, até então, uma das certezas da racionalidade moderna. 
Enquanto Einstein problematizou as leis de Newton no domínio da astrofísica, a mecânica quântica estudou-as no âmbito da microfísica e constituiu a segunda condição teórica de estabilização da ontologia do presente como postura diante da constituição dos saberes. Pensadores como Heisenberg e Bohr chegaram à conclusão de que é impossível observar ou medir um objeto sem modificalo. De acordo com o princípio da incerteza de Heisenberg (1971, 1980, apud Santos, 1997, p. 26), não se podem reduzir simultaneamente os erros da medição da velocidade e da posição das partículas; o que for feito para reduzir o erro de uma das medições aumenta o erro da outra. Assim, a intervenção do pesquisador é uma ação que "contamina" o objeto de pesquisa e o faz diferente do que era antes de iniciado o processo.

A partir do precedente que a mecânica quântica abriu ao conseguir expor o problema da rigorosidade das medições, o terceiro rombo na concepção científica baseada na analítica da verdade advirá da dúvida sobre o rigor da matemática, o veículo formal de demonstração das mesmas medições. Gödel, com o teorema da incompletude e os teoremas sobre a impossibilidade, demonstrou que, em determinados casos, mesmo seguindo as normas da lógica matemática, proposições indecidíveis podem ser criadas. Uma dessas proposições que não podem ser comprovadas ou contestadas é, exatamente, a que define o caráter não contraditório do sistema.

A quarta condição de crise da racionalidade moderna é emplacada por novidades trazidas nas esferas da microfísica, da química e da biologia. Santos (1997, p. 27-28), a título de exemplo, menciona a teoria das estruturas dissipativas do químico Ilya Prigogine. Segundo a teoria das estruturas dissipativas, em sistemas que funcionam nas margens da estabilidade, a evolução explica-se por flutuações de energia que em momentos específicos, impassíveis de inteira previsão, produzem reações que através de mecanismos não lineares, pressionam o sistema para além de um limite máximo de instabilidade e o conduzem a um novo estado macroscópico. Com as análises de Prigogine sobre a irreversibilidade nos sistemas abertos, passamos a compreender que tais sistemas devem ser entendidos como produto da sua história. ${ }^{6}$ Santos (1997, p. 28) afirma que a teoria de Prigogine, não é um fenômeno isolado, mas que faz parte de um movimento contemporâneo que instaura uma:

nova concepção da matéria e da natureza que propõe, uma concepção dificilmente compaginável com a que herdamos da física clássica. Em vez da eternidade, a história; em vez do determinismo, a imprevisibilidade; em vez do mecanicismo, a interpenetração, a espontaneidade e a auto-organização; em vez da reversibilidade, a irreversibilidade e a evolução; em vez da ordem, a desordem; em vez da necessidade, a criatividade e o acidente.

Seguindo essa dinâmica do pensamento contemporâneo, em detrimento da matriz cartesiana, propomos a cartografia como um tipo de conhecimento gerado e, só assim, em consonância construtiva com a heterogeneidade imanente ao viver, isto é, pautado por uma ética, uma estética e uma política que, além de 
favorecer o desprendimento das rotas repetidas, apure nosso cuidado com o outro através do respeito pela própria vida e sua vocação expansiva. Pensamos a ética, a estética e a política como ferramentas de subversão do que aparece como verdade natural e aprisiona a produção da diferença.

A cartografia deve conformar estratégias de produção de saberes que extravasem a busca pelo conhecimento verdadeiro, em direção ao conhecimento que funcione para atualizar as intensidades minoritárias, aquelas que corajosamente nos produzem um mal-estar, justamente porque nos arrancam do que éramos antes delas. A força do desejo, quando tem possibilitada sua conexão com a realidade, atinge o poder de romper com todas as generalizações, tantas vezes repetidas e por isso acreditadas. Entre elas, a verdade heterossexual sobre o amor, a verdade identitária sobre os sujeitos, a verdade racional sobre o pensamento ou mesmo a verdade competitiva sobre a prática esportiva.

Encaramos a cartografia como uma "máquina de guerra" porque sua função é a de produzir o produzir, agindo por sistema de cortes e fluxos, importando o que se faz dela, o que faz em si mesma enquanto passeia em acontecimentos. O conceito máquina de guerra foi cunhado por Deleuze e Guattari (1995) e remonta às maneiras de pensar e de viver nômades. Pensamento e vida de origem e natureza divergentes na relação com os modos de subjetivação preconizados pelo aparelho de Estado. Divergentes porque, em detrimento de serem definidos como o Estado, por excelência conservadorista, preocupado com a sua reprodução idêntica através da manutenção das instâncias de poder, a máquina de guerra nômade funciona resguardada pelos laços das alianças, mas ofendendo os movimentos de interiorização e integração estatal.

Perceba que não estamos afiançando a ideia de que qualquer um dos dois, aparelho de Estado ou máquina de guerra nômade, existam absolutamente, isto é, oponham-se enquanto sociedades estatais e contraestatais. Deleuze e Guattari (1995) mostram que o Estado soberano sempre esteve em relação com um fora e que, portanto, em vez da lei do tudo ou nada, tanto um como o outro, existem em convívio infinito sob a lei do interior e do exterior.

A máquina vai à guerra para impedir que o Estado soberano consiga a sua anexação e consequente sedentarização, porque só desse jeito pode manter-se metamorfoseando em seu nomadismo, ativando, na qualidade de corpo coletivo minoritário, por exemplo, uma nova forma de fazer ciência. Assim, queremos afirmar que a potência nômade não pertence unicamente aos bárbaros, mas a todos os grupos que se insurgem contra um fenômeno hegemônico.

Será possível fazer uma analogia entre o aparelho de Estado e a ciência régia, como vimos criticando até agora? Sob que regime, então, funcionaria uma ciência nômade? Quais suas diferenças em relação à ciência régia que parece tomar por objeto a figura e o funcionamento do aparelho de Estado? Qual o sentido de propormos a máquina de guerra cartográfica como estratégia de produção alternativa do conhecimento? 
Como os povos bárbaros, o cientista nômade está obrigado a agir também em relação à ciência com as especificidades das organizações estatais. Ele está no meio, entre a máquina de guerra, que, como dizem Deleuze e Guattari (1995, p. 27), "o alimenta e o inspira", e o Estado, "que lhe impõe uma ordem de razões". O pensamento nômade o empurra a agir em consonância com o inesperado, o ainda impensado, enquanto o pensamento sedentário o quer trazer de volta "[...] a regras civis e métricas que vão limitá-la [a máquina de guerra] de modo estrito, controlar, localizar a ciência nômade, e proibi-la de desenvolver suas conseqüências através do campo social." (DELEUZE; GATTARI, 1995, p. 27) O trabalho do cientista nômade precisa ser o de embrenhar-se nesse interstício para afirmar os devires, explodir teoremas e axiomas que nivelam as contradições e as transformam em categorizações. Só pela via da guerra que a máquina pode, novamente, construir um espaço liso para trafegar.

A cartografia tem essa função de romper as estratificações, o espaço estriado, as leis empoeiradas que guardam a função política de controlar os movimentos sociais para assegurar a manutenção do Estado. O rompimento com as certezas acadêmicas que amainam os movimentos da multidão, ${ }^{8}$ cria coeficientes de indeterminação, espaços lisos por onde por meio do conhecimento que nasce das próprias multidões, a vida atinge a sua potência máxima porque pode transformar-se segundo as suas próprias prerrogativas e não mais segundo os autoritarismos do Estado ou do capital. Para tanto, como apontam Deleuze e Guattari (1995), precisamos colocar as variáveis científicas em estado de variação contínua.

Enquanto a metodologia racional prevê um percurso que deve ser seguido de um ponto a outro, as estratégias cartográficas precisam ocupar um espaço liso marcado pela exterioridade, pela intuição e por revezamentos onde não há nem medidas nem reproduções aceitáveis. Deleuze e Guattari (1995, p. 48) definem o pensamento nômade como:

um pensamento-acontecimento, hecceidade, em vez de um pensamento-sujeito, um pensamento problema no lugar de um pensamento-essência ou teorema, um pensamento que faz apelo a um povo em vez de se tomar por um ministério.

A cartografia é traçada de forma peculiar porque a máquina de guerra quando acionada assume dupla função: primeiro a de descompressão do espaço, inclusive conceitual, e depois a de intensificação das rotas e dos movimentos por todos os lados. O aniquilamento das forças do Estado não significa o despovoamento do espaço, e sim fazer crescer o "deserto", a "estepe" onde a produção do conhecimento possa se dar mais livremente, sem fronteiras delimitadas e necessidade de passaportes conceituais.

Como estamos propondo, as cartografias, além de extensivas, ou seja, de relacionarem-se a um espaço constituído por trajetos, são intensivas, fazendo ver e falar o que subentende os trajetos: as forças. A cartografia de intensidades distribui as forças, ou seja, é um instrumento que, ao ser proposto, interpõe-se ao cartógrafo e ao plano de intervenção, ao mesmo tempo que, paradoxalmente, 
eles aceitam colocar-se em causa, encontrar-se. Nesse encontro, tanto um como o outro, podem, na feitura, avaliação e transformação coexistentes ao fazer cartográfico, questionar as posturas viciadas e conservadoras, agir sobre as forças, dobrando-as. Podem, assim, lançar-se num devir que os arrasta e impele a forjar caminhos-diferença, habitar linhas de fuga.

\section{Notas}

${ }^{1}$ Conforme Machado (2000), a expansão da vida tem relação com o desmanchar de formas dadas, do que se tornou instituído e permanece movendo processos burocratizantes com relação aos valores, às regras, ao trabalho, ao amor, à amizade etc.

${ }^{2} \mathrm{O}$ conceito “anomalia” é trabalhado por Georges Canguilhem (1990) no livro O normal e o patológico.

${ }^{3}$ A atitude transdisciplinar visa a produzir interferências desestabilizadoras entre quaisquer domínios compartimentados - sejam filosóficos, teóricos, políticos, artísticos etc. Este investimento desestabilizador mina as fronteiras dos campos e permite o engendramento de novos saberes e novas práticas por hibridizações.

${ }^{4}$ Nossas análises sobre as contribuições filosóficas do pensamento pré-socrático são embasadas pelo artigo "Saúde, desejo e pensamento", publicado por Luiz Antonio Fuganti no ano de 1990.

${ }^{5}$ De acordo com Santos (1997, p. 27), o impacto dos teoremas de Gödel na filosofia da ciência tem sido diversamente avaliado. Cfr., por exemplo, J. Ladrière (1967); R. Jones (1982); J. ParainVial (1983); R. Thom (1985); J. Briggs e F. D. Peat (1985).

${ }^{6}$ De acordo com Santos (1997, p. 28), podemos encontrar análises sobre essa temática através de estudos, tais como: I. Prigogine e I. Stengers (1979); I. Prigogine (1980, 1981).

${ }^{7}$ Conforme Barros e Passos (2000), a noção de acontecimento remete-se ao que produz rupturas, que catalisa fluxos, que produz análise, que decompõe. Refere-se às múltiplas relações que compõe o campo nos níveis da intervenção e da análise. Um conceito que denota, segundo Scherér (2000), a sabotagem da vivência de uma individualidade por demais maciça, a dissolução do ego pelo atravessamento de singularidades moleculares, moventes ou nômades, que se destacam de um campo transcendental. O que está colocado é o rompimento com o "Eu penso" da tradição cartesiana, e mesmo toda consciência, para formar um campo transcendental impessoal, também chamado de plano de imanência que toca na junção do mais impessoal com o mais singular.

${ }^{8}$ Conforme Hardt e Negri (2001), a multidão comporta singularidades, sendo, portanto, um movimento desejante antagônico a qualquer forma de dominação. Diferentemente da ide $\square$ ia de povo, que reflete uma homogeneidade interna que se acomoda à soberania, a multidão constituise como plano múltiplo e inconclusivo, buscando sempre a efetuação universal de práticas livres e produtivas.

\section{REFERÊNCIAS}

BARROS, R. B.; PASSOS, E. A construção do plano da clínica e o conceito de transdisciplinaridade. Revista Teoria e Pesquisa - UNB, Brasília, v. 16, n. 1, p. 71-79, abr. 2000.

BENJAMIN, W. Parigi capitale del XIX secolo. Torino: Einaudi, 1986.

BRIGGS, J.; PEAT, F. D. Looking glass universe: the emergings of wholeness. Londres: Fontana, 1985.

CALlADO, A. Quarup. Rio de Janeiro: Civilização Brasileira, 1978. 
CANGUILHEM, G. O normal e o patológico. Rio de Janeiro: Forense Universitária, 1990.

DELEUZE, G.; GUATTARI, F. Mil platôs: capitalismo e esquizofrenia. Rio de Janeiro: Editora 34, 1995. v. 5.

FOUCAULT, M. Dits et Écrits. Paris: Gallimard, 1994. v. 4.

FUGANTI, L. A. Saúde, desejo e pensamento. In: LANCETTI, A. (Ed.). Saúde e Loucura. São Paulo: Hucitec, 1990, v. 2, p. 19-82.

GIACOMEL, A. et al. Conhecimento e cartografia: tempestade de possíveis. In: FONSECA, T.; KIRST, P. (Ed.). Cartografias e devires: a construção do presente. Porto Alegre: UFRGS, 2003. p. 91-101.

HARDT, M.; NEGRI, A. Império. Rio de Janeiro: Record, 2001.

JONES, R. Physics as metaphor. Nova Iorque: New American Library, 1982.

LADRIÈRE, J. Les limites de la formalization. In: PIAGET, J. (Ed.). Logique et connaissance scientifique. Paris: Gallimard, 1967.

LAVRADOR, M. C. Interfaces do saber psi. In: BARROS, M. E. B. (Ed.). Psicologia: questões contemporâneas. Vitória: Edufes, 1999. p. 15-58.

MACHADO, R. Foucault, a filosofia e a literatura. Rio de Janeiro: J. Zahar, 2000.

MORIN, E. Epistemologia da Complexidade. In: SCHNITMAN, D. F. (Ed.). Novos paradigmas, cultura e subjetividade. Porto Alegre: Artmed, 1996. p. 274289.

ORTIZ, R. Walter Benjamin e Paris: individualidade e trabalho intelectual. Revista Tempo Social, São Paulo, v. 12 , n. 1, p. 11-28, maio 2000.

PARAIN-VIAL, J. Philosophie des sciences de la nature: tendances nouvelles. Paris: Klincksieck, 1983.

PESSOA, F. Ficções do interlúdio. São Paulo: Companhia das Letras, 1998.

PRIGOGINE, I.; STENGERS, I. La nouvelle alliance: metamorphose de la science. Paris: Gallimard, 1979.

PRIGOGINE, I. From being to becoming. San Francisco: Freeman, 1980. 
PRIGOGINE, I. Time, irreversibility and randomness. In: JANTSCH, E. (Ed.). The evolutionary vision. Boulder: Westview Press, 1981. p. 73-81.

ROLNIK, S. Cartografia sentimental: transformação contemporânea do desejo. São Paulo: Estação Liberdade, 1989.

SANTOS, B. S. Um discurso sobre as ciências. Porto: Afrontamento, 1997.

SCHERÉR, R. Homo tantum - o impessoal: uma política. In: ALLIEZ, E. (Ed.). Gilles Deleuze: uma vida filosófica. São Paulo: Editora 34, 2000. p. 21-38.

THOM, R. Parábolas e catástrofes. Lisboa: D. Quixote, 1985.

Recebido em: 18 de agosto de 2010 Aceito em:18 de abril de 2012| 